\title{
Does grey wolf presence affect habitat selection of wolverines?
}

\author{
Anni Koskela ${ }^{1, *}$, Salla Kaartinen², Jouni Aspi ${ }^{1}$, Ilpo Kojola², Pekka Helle ${ }^{2}$ \& \\ Seppo Rytkönen ${ }^{1}$
}

1) Department of Biology, P.O. Box 3000, Fl-90014 University of Oulu, Finland $\left({ }^{*}\right.$ corresponding author's e-mail: anni.koskela@oulu.fi)

2) Finnish Game and Fisheries Research Institute, P.O. Box 413, Fl-90014 University of Oulu, Finland

Received 27 Apr. 2012, final version received 31 Jan. 2013, accepted 1 Mar. 2013

Koskela, A., Kaartinen, S., Aspi, J., Kojola, I., Helle, P. \& Rytkönen, S. 2013: Does grey wolf presence affect habitat selection of wolverines? - Ann. Zool. Fennici 50: 216-224.

Scavengers can improve their foraging possibilities by associating with predators that provide food. Therefore, the presence of grey wolves (Canis lupus) may increase scavenging opportunities for wolverines (Gulo gulo). There have been many observations of wolverines utilizing wolf-killed moose (Alces alces), but quantitative information is lacking. We analysed wolverine and wolf habitat selection in eastern Finland, where the two species are sympatric. Generalized linear mixed-effect models were constructed to explain the location of wolverines in terms of their distance from settlements, the forest type and the presence of wolves. We found that wolverines favoured wolf presence, coniferous forests, mixed forests and mires; and avoided settlements, young forests and deciduous forests. These findings improve our understanding of wolverine habitat selection by demonstrating the importance of remote forest areas, as well as the presence of other carnivore species, to wolverines in boreal forests in Finland.

\section{Introduction}

Scavengers exploit carcasses, which are conventionally considered an ephemeral, rare and unpredictable resource in terms of their spatiotemporal availability (e.g. Heinrich 1988, Wilmers et al. 2003, Wilmers \& Post 2006, Baglione \& Canestrari 2009, DeVault et al. 2011). One foraging strategy that scavengers can employ to discover unpredictable food sources is to associate with predators that provide food (Stahler et al. 2002). Availability of carrion from the kills by predators and hunters may be much more predictable, especially for those scavenger species associating with large predators (Stahler et al. 2002, Wilmers et al. 2003, Selva et al. 2005). Other advantages of such strategy include a reduced searching time, decreased energy expenditure and access to large, high-quality food items (Brockmann \& Barnard 1979, Heinrich 1988). On the other hand, predators can also be a threat to scavengers (White et al. 2002, Ballard et al. 2003). Benefits of scavenging possibly outweigh the associated risk of being killed by a predator (Paquet 1992, van Dijk et al. 2008a, Gorini et al. 2012). 
The presence of grey wolves (Canis lupus) may increase the scavenging opportunities for wolverines (Gulo gulo). There have been many observations of wolverines utilizing wolf-killed moose (van Dijk et al. 2008a, 2008b), but quantitative information is lacking. Within our study area in eastern Finland, the wolverine is sympatric with the grey wolf. Approximately 50\% of Finnish wolverines live in northern Finland, where - as in northern Scandinavia - semidomesticated reindeers (Rangifer tarandus tarandus) are most probably their primary prey (cf. Myhre \& Myrberget 1975, Landa et al. 1997, Mattisson et al. 2011a). The other half of the population is distributed south of the reindeer management area, in eastern and central Finland. In this area, wolverines might be more dependent on carrion, wolf-killed moose (Alces alces), and self-hunted smaller prey, such as mountain hares (Lepus timidus), grouse and small rodents, as observed in southern Norway (van Dijk et al. 2008b).

The wolverine is a terrestrial mustelid that has a circumpolar distribution corresponding with the arctic and subarctic regions and also boreal forests of Eurasia and North America (Landa et al. 2000, Copeland et al. 2010). Urban development, human disturbance and persecution have contributed to the currently restricted distribution of the wolverine (Banci 1994, Copeland 1996, Carroll et al. 2001, Persson et al. 2009). The wolverine is often viewed as being a high alpine dweller for which anthropogenic factors, probably due to persecution (Persson et al. 2009), are more important in the selection of the home range than habitat factors (May et al. 2006). Wolverine habitat selection is negatively affected by human activity, including roads and backcountry recreation (Caroll et al. 2001, Rowland et al. 2003, May et al. 2006, Krebs et al. 2007). Factors such as the density of prey and landscapes where they can find a suitable denning habitat are also important (Landa et al. 2000, May et al. 2010, 2012).

In this study, we examined the effect of wolf presence on the habitat selection on wolverines. We also studied how settlements and forest type affect the habitat selection of wolverines and wolves in boreal forests of eastern Finland. We expected wolverines to prefer habitats where

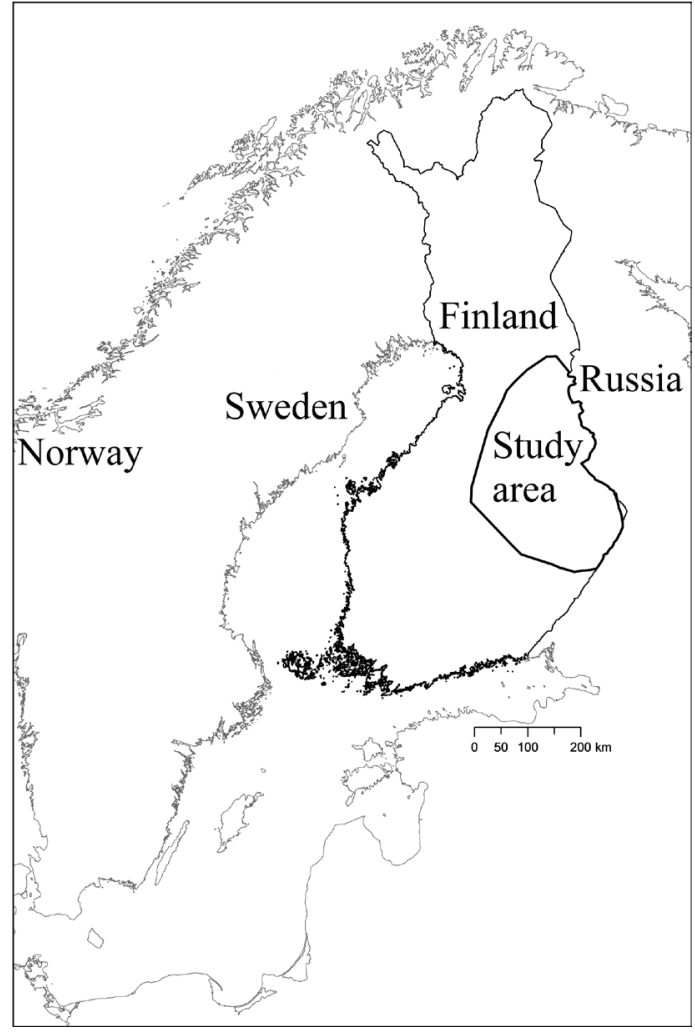

Fig. 1. Locaion of the study area in eastern Finland.

wolves may increase their scavenging opportunities. Furthermore, we expected both study species to avoid settlements.

\section{Material and methods}

\section{Study area}

Our study area was located in three provinces of eastern Finland (Kainuu, North Karelia and North Savonia) (Fig. 1) covering an approximate area of $56000 \mathrm{~km}^{2}$. This area belongs to the midboreal coniferous-forest zone and has a mildly continental climate (Ahti et al. 1968). The elevation (a.s.l.) of the study area ranges from 160 to $380 \mathrm{~m}$. The landscape is mainly comprised of boreal forests, lakes and mires. About $80 \%$ of the land area is covered by forests, the dominant tree species being the Scots pine (Pinus sylvestris) and the Norway spruce (Picea abies). Extensive forest harvesting has been carried out in the 
study area and young mixed forests are common. Altogether, $1.8 \%$ of the study area is protected. The average density of humans in the study area is five people per $\mathrm{km}^{2}$. Human infrastructure is mainly constrained near to town centres and small villages, but many people have summer houses outside these areas.

The densities of both study species in the study area are similar: 3 animals per $1000 \mathrm{~km}^{2}$. The Finnish wolverine population is estimated at a minimum of 155-170 individuals. The total wolf population in Finland is estimated at a minimum of 150-160 individuals, and the population has been decreasing since 2006 when it peaked at 250-300 wolves. Based on the IUCN criteria (Rassi et al. 2010), the wolverine is classified as a critically endangered (CR) species in Finland. The conservation status of wolf in Finland is endangered (EN). Potential wolverine prey species within our study area are wild forest reindeer (Rangifer t.fennicus), grouse, mountain hare, beavers and small rodents. The primary prey of wolves is the moose (Kojola et al. 2004).

\section{Wildlife triangle data}

Wolverine and wolf locations were derived from the wildlife-triangle count data gathered in eastern Finland during 2005-2009. Wildlife triangles are equilateral triangles with a perimeter of $12 \mathrm{~km}$, developed and organized by the Finnish Game and Fisheries Research Institute (FGFRI) in cooperation with the Hunter's Central Organization. Data on abundance levels and temporal changes of some 30 wildlife species in about 1000 locations scattered throughout Finland are gathered annually along these triangles (Lindén et al. 1996, Pellikka et al. 2005). During the census, the tracks of mammals crossing the triangle line are recorded and an index of the abundance for each species is given as the track density (tracks/10 km/day).

In this study, the data consisted of all geographic coordinates of triangle-line crossings by wolverines and wolves (with an accuracy of $50 \mathrm{~m}$ ) within the study area. Altogether, 885 triangles were counted and tracks of wolverines and/or wolves were found in 146 of them. As control plots, we selected an equal number of random crossings from existing wildlife triangles in our study area in order to determine whether wolverines seek areas in close proximity to wolves.

\section{Landscape data}

To determine the factors behind wolverine and wolf habitat selection, we selected landscape variables representing both infrastructural features (settlements) and the main habitat types in Finland. The habitat data were based on the CORINE Land Cover 2000 database provided by the Finnish Environment Institute (SYKE). The database covers the entire area of Finland, and has a minimum mapping unit of 25 hectares. It is based on the automated interpretation of satellite images and data integration with existing digital map data. The CORINE data used in this study comprised six classes of land cover variables: (1) settlements, (2) mixed forests, (3) coniferous forests, (4) deciduous forests, (5) young forests and (6) mires (Table 1). Settlements were entered into the models as the distance of a given crossing or control plot from the nearest settlement. Other landscape variables were measured as the proportion of each habitat

Table 1. Landscape classifications used in the study.

\begin{tabular}{llc}
\hline Class & Class loading & Tree crown cover (\%) \\
\hline Settlements & Continuous and discontinuous urban fabric & - \\
Mixed forests & Conifers and deciduous trees $>70 \%$ & $>30$ \\
Coniferous forests & Conifers $>70 \%$ & $>30$ \\
Deciduous forests & Deciduous trees $>70 \%$ & $>30$ \\
Young forests & Young successional stages: plantations and clearcuts & $10-30$ \\
Mires & Inland marshes and peat bogs & $<30$ \\
\hline
\end{tabular}


type around the crossing or control plot within a given radius. These six variables were included in the analysis of wolf habitat selection. The seventh variable that was included in the analysis of wolverine habitat selection was the distance of a given wolverine crossing or control plot from the nearest wolf crossing.

To determine the scale at which the landscape variables were most important in predicting the wolverine occurrence, we constructed buffers around the wolverine and control plots whose radii were $75,150,300,600,1200,2400$ and $4800 \mathrm{~m}$. We then fitted generalized linear models for each buffer radius using landscape variables as predictive variables. For later models, we used only the most significant buffer radius.

\section{Statistical analysis and modelling process}

Before modelling, to identify possible multicollinearities we carried out Spearman's pairwise correlation analysis between the explanatory variables. As there were no strongly correlated variables $(|r|<0.6)$, they were all included in the models (Green 1979, Fielding \& Haworth 1995, Sawyer et al. 2006, Klar et al. 2008).

Our habitat selection analysis was based on an information-theoretic approach in which hypotheses are first specified and mathematically formulated. These alternative hypotheses are then ranked according to their parsimony (Johnson \& Omland 2004, Rushton et al. 2004, Greaves et al. 2006, Klar et al. 2008). We designed a set of 128 candidate models of the occurrence of wolverines and wolves based on the following general hypotheses: (1) wolverines seek areas in proximity to wolves (May et al. 2008, van Dijk et al. 2008a, 2008b); and (2) wolverines and wolves avoid settlements where human presence is continuous (May et al. 2006, Krebs et al. 2007, Kaartinen et al. 2010).

We used a logistic regression together with Akaike's Information Criterion corrected for small sample sizes $\left(\mathrm{AIC}_{\mathrm{c}}\right)$ to model the important habitats for wolverines and wolves in the study area. Selection of the best approximating models was based on the $\Delta \mathrm{AIC}_{\mathrm{c}}$ values, which were calculated as the differences between the current and minimum values of the model $\mathrm{AIC}_{\mathrm{c}}$ (Burnham \& Anderson 2002). $\triangle \mathrm{AIC}_{\mathrm{c}}$ expresses the information loss experienced when using the fitted model $g_{i}$ rather than the best model $g_{\text {min }}$ for inference (Burnham \& Anderson 2004). We also calculated the Akaike weights $(w)$ for all the models. The Akaike weight is a measure of the likelihood of a model for the given data (Johnson $\&$ Omland 2004), so that models with a larger $w_{i}$ better approximate the data (see Burnham \& Anderson 2002). The primary objective in model fitting was to assess the relative importance of the seven variables included.

Because there was considerable model selection uncertainty in our data, we used the method suggested by Burnham and Anderson (2002) to quantify the evidence for the importance of each variable. We summed Akaike weights across all the models in which individual variables attained the relative importance. The larger the sum of the Akaike weights, the more important a variable was relative to the other variables considered. We used model averaging to produce the best model, including aspects of a number of models (Greaves et al. 2006). In the set of best approximating models, parameter estimates and their standard errors were examined to assess the reliability of each variable as a predictor of the occurrence of a wolverine or wolf. Due to the uncertainty in model selection, the modelaveraged slopes $(\beta)$ of the variables and their standard errors were calculated using equations 4.1 and 4.9 in Burnham and Anderson (2002); models with $\Delta \mathrm{AIC}_{\mathrm{c}}<4$ were included. Statistical analyses were carried out using $\mathrm{R}$ ver. 2.12.1 ( $\mathrm{R}$ Development Core Team 2010) with the package MuMIn (Barton Kamil 2010).

\section{Results}

Among the wildlife triangles counted in our study area $(n=885)$, we found evidence of wolverines and/or wolves in 146 triangles. Altogether, 109 wolverine and 59 wolf tracks were observed (Table 2). The significance of the models increased when the buffer radius grew, and the landscape variables were most important in predicting wolverine occurrence when the buffer radius around the wolverine 


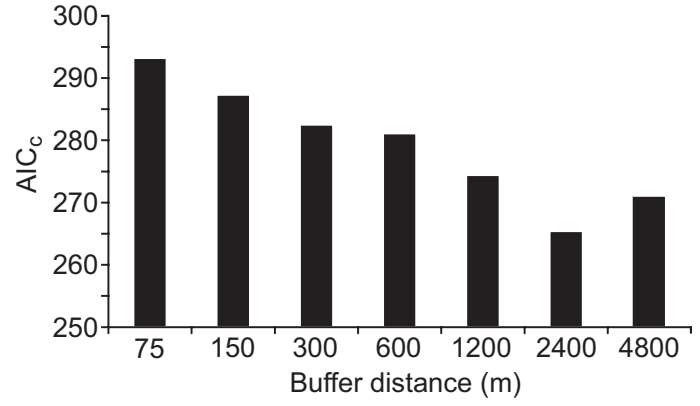

Fig. 2. $A I C$ values for different buffer distances around the wolverine and control plots.

and control plots was $2400 \mathrm{~m}\left(\Delta \mathrm{AIC}_{\mathrm{c}}=265.72\right)$ (Fig. 2). When the buffer radius was greater than $2400 \mathrm{~m}$, the significance of the models started to decrease.

The model best explaining wolverine habitat selection included as explanatory variables

Table 2. Records of wolverines and grey wolves in wildlife-triangle counts within the study area in 2005-2009.

\begin{tabular}{lrr}
\hline Year & Wolverine & Wolf \\
\hline 2005 & 28 & 16 \\
2006 & 21 & 11 \\
2007 & 16 & 14 \\
2008 & 19 & 8 \\
2009 & 25 & 10 \\
TOTAL & 109 & 59 \\
\hline
\end{tabular}

the distance from wolf crossing, deciduous forests and distance from settlements (Table 3). Altogether, 15 models had $\triangle \mathrm{AIC}_{\mathrm{c}}$ values lower than 4 , and all of them included the distance from wolf crossing and deciduous forests. Other explanatory variables in the top models were settlements ( 8 models), mixed forests ( 7 models), mires (4 models), coniferous forests (4 models) and young forests (3 models).

The model best explaining wolf habitat selection consisted of settlements, coniferous forests and mixed forests (Table 4). $\triangle \mathrm{AIC}_{\mathrm{c}}$ values were lower than 4 in 24 models, and all of them included distance to settlements. Other explanatory variables in the top models were coniferous forests (12 models), young forests (12 models), mixed forests (10 models), deciduous forests (10 models) and mires (8 models).

Wolverines seemed to favour wolf presence, coniferous forests, mixed forests and mires; and avoided settlements, young forests and deciduous forests (Table 5). Wolves preferred quite similar habitats to those of wolverines: they favoured coniferous and mixed forests; and avoided settlements, young forests and deciduous forests. Wolves, unlike wolverines, also avoided mires.

\section{Discussion}

One important factor in wolverine habitat selec-

Table 3. Models best explaining wolverine habitat selection $\left(\triangle \mathrm{AIC} \mathrm{c}_{\mathrm{c}}<4\right)$. The models are ranked according to the $\mathrm{AIC}_{\mathrm{c}}$ values.

\begin{tabular}{|c|c|c|c|c|c|}
\hline Rank & Model & $\mathrm{AIC}_{\mathrm{c}}$ & $\Delta \mathrm{AIC}_{\mathrm{c}}$ & $w$ & df \\
\hline 1 & deciduous $\times$ settlements $\times$ wolf & 249.9 & 0.000 & 0.152 & 4 \\
\hline 2 & deciduous $\times$ settlements $\times$ wolf $\times$ mixed & 250.7 & 0.787 & 0.103 & 5 \\
\hline 3 & deciduous $\times$ wolf & 251.4 & 1.456 & 0.074 & 3 \\
\hline 4 & deciduous $\times$ settlements $\times$ wolf $\times$ mires & 251.9 & 2.018 & 0.056 & 5 \\
\hline 5 & deciduous $\times$ coniferous $\times$ settlements $\times$ wolf & 252.0 & 2.073 & 0.054 & 5 \\
\hline 6 & deciduous $\times$ settlements $\times$ wolf $\times$ young & 252.0 & 2.084 & 0.054 & 5 \\
\hline 7 & deciduous $\times$ wolf $\times$ mixed & 252.1 & 2.183 & 0.051 & 4 \\
\hline 8 & deciduous $\times$ coniferous $\times$ settlements $\times$ wolf $\times$ mixed & 252.3 & 2.423 & 0.045 & 6 \\
\hline 9 & deciduous $\times$ settlements $\times$ wolf $\times$ mixed $\times$ young & 252.8 & 2.858 & 0.037 & 6 \\
\hline 10 & deciduous $\times$ settlements $\times$ wolf $\times$ mires $\times$ mixed & 252.8 & 2.898 & 0.036 & 6 \\
\hline 11 & deciduous $\times$ wolf $\times$ mires & 253.3 & 3.333 & 0.029 & 4 \\
\hline 12 & deciduous $\times$ wolf $\times$ young & 253.4 & 3.453 & 0.027 & 4 \\
\hline 13 & deciduous $\times$ coniferous $\times$ wolf & 253.4 & 3.494 & 0.027 & 4 \\
\hline 14 & deciduous $\times$ wolf $\times$ mires $\times$ mixed & 253.8 & 3.841 & 0.022 & 5 \\
\hline 15 & deciduous $\times$ coniferous $\times$ wolf $\times$ mixed & 253.8 & 3.854 & 0.022 & 5 \\
\hline
\end{tabular}


Table 4. Models best explaining wolf habitat selection $\left(\Delta A I C_{c}<4\right)$. The models are ranked according to the $A I C_{c}$ values.

\begin{tabular}{|c|c|c|c|c|c|}
\hline Rank & Model & $\mathrm{AIC}_{\mathrm{c}}$ & $\Delta \mathrm{AIC}_{\mathrm{c}}$ & $w$ & df \\
\hline 1 & settlements $\times$ coniferous $\times$ mixed & 158.7 & 0.00 & 0.098 & 4 \\
\hline 2 & settlements $\times$ coniferous & 159.3 & 0.61 & 0.072 & 3 \\
\hline 3 & settlements $\times$ young & 160.0 & 1.31 & 0.051 & 3 \\
\hline 4 & settlements & 160.0 & 1.39 & 0.049 & 2 \\
\hline 5 & deciduous $\times$ settlements $\times$ young & 160.1 & 1.41 & 0.049 & 4 \\
\hline 6 & settlements $\times$ coniferous $\times$ mixed $\times$ young & 160.4 & 1.78 & 0.040 & 5 \\
\hline 7 & settlements $\times$ coniferous $\times$ young & 160.5 & 1.81 & 0.040 & 4 \\
\hline 8 & settlements $\times$ coniferous $\times$ mires $\times$ mixed & 160.5 & 1.87 & 0.039 & 5 \\
\hline 9 & deciduous $\times$ settlements $\times$ coniferous $\times$ mixed & 160.6 & 1.98 & 0.037 & 5 \\
\hline 10 & deciduous $\times$ settlements $\times$ mires $\times$ young & 161.0 & 2.34 & 0.030 & 5 \\
\hline 11 & deciduous $\times$ settlements $\times$ coniferous & 161.0 & 2.36 & 0.030 & 4 \\
\hline 12 & deciduous $\times$ settlements & 161.0 & 2.39 & 0.030 & 3 \\
\hline 13 & settlements $\times$ mixed & 161.1 & 2.48 & 0.028 & 3 \\
\hline 14 & settlements $\times$ mixed $\times$ young & 161.3 & 2.66 & 0.026 & 4 \\
\hline 15 & settlements $\times$ coniferous $\times$ mires & 161.3 & 2.66 & 0.026 & 4 \\
\hline 16 & settlements $\times$ mires & 161.3 & 2.69 & 0.026 & 3 \\
\hline 17 & settlements $\times$ mires $\times$ young & 161.4 & 2.76 & 0.025 & 4 \\
\hline 18 & deciduous $\times$ settlements $\times$ mixed $\times$ young & 161.6 & 2.93 & 0.023 & 5 \\
\hline 19 & deciduous $\times$ settlements $\times$ coniferous $\times$ young & 161.6 & 2.94 & 0.023 & 5 \\
\hline 20 & deciduous $\times$ settlements $\times$ mires & 161.9 & 3.28 & 0.019 & 4 \\
\hline 21 & deciduous $\times$ settlements $\times$ coniferous $\times$ mixed $\times$ young & 162.1 & 3.45 & 0.017 & 6 \\
\hline 22 & deciduous $\times$ settlements $\times$ mixed & 162.2 & 3.58 & 0.016 & 4 \\
\hline 23 & settlements $\times$ coniferous $\times$ mires $\times$ young & 162.5 & 3.83 & 0.014 & 5 \\
\hline 24 & settlements $\times$ coniferous $\times$ mires $\times$ mixed $\times$ young & 162.5 & 3.85 & 0.014 & 6 \\
\hline
\end{tabular}

tion was the distance from wolf crossing. As expected, wolverines preferred areas close to wolf territories, which may partly be due to greater carrion availability. Wolverines are known to utilize carcasses left by wolves (van Dijk et al. 2008a, 2008b) and lynx (Mattisson et al. 2011a, 2011b). Van Dijk et al. (2008a) found that wolverines do not directly follow the tracks of other carnivores to carcasses, but their movements become more tortuous after encountering the tracks. Landa and Skogland (1995) found that the removal of wolves resulted in a decrease in wolverine numbers in the same area in Norway, because less carrion was available. According to van Dijk et al. (2008b), the proportion of moose increased in the diet of Norwegian wolverines when wolves were present in the same range, because wolverines started to eat animals killed by the wolves. In Finland, the wolf population has been declining for the last five years. Although the wolverine population size in Finland has remained stable during recent years, decreasing wolf numbers might have a negative effect in the long term.
Wolves can also be a threat to wolverines (White et al. 2002). Eight of fourteen documented wolf-wolverine interactions in North America resulted in the death of the wolverine (Ballard et al. 2003). Accordingly, wolverines might occupy the same regions as wolves because of greater carrion availability, but not live in very close proximity to them in order to avoid intra-guild predation. The interaction

Table 5. Model-averaged coefficients for the best wolverine and wolf models. Landscape variables: negative values indicate avoidance, positive values refer to favouring. Distance to settlements and distance to wolf area: negative values indicate favouring, positive values avoidance.

\begin{tabular}{lrr}
\hline Variables & Wolverine & Wolf \\
\hline Deciduous forests & -34.571 & -6.591 \\
Mixed forests & 2.361 & 3.953 \\
Coniferous forests & 0.442 & 3.244 \\
Young forests & -0.467 & -3.486 \\
Mires & 0.139 & -1.114 \\
Settlements & 0.0005 & 0.0008 \\
Wolf presence & -0.00004 & \\
\hline
\end{tabular}


between wolverines and wolves can be seen as a trade-off situation, in which wolverines are trying to maximize both their survival and foraging possibilities (van Dijk et al. 2008a).

Other sources, such as other large carnivores (brown bear and Eurasian lynx), can also provide carrion for wolverines but they are probably not as important as wolves. Brown bears hibernate in winter, when reproducing female wolverines have the greatest requirement for food. The primary prey species of Eurasian lynx in eastern Finland are the mountain hare and grouse (Pulliainen et al. 1995), which are smaller prey items and do not, therefore, provide significant resources for wolverines.

Moose and other carcasses also become available for wolverines through hunter harvesting, ecotourism, vehicle collisions and natural death. Remains following the hunter harvest were reported to be the largest food source for scavengers in Scandinavia (Wikenros 2011). The largest biomass from moose carcasses available to scavengers occurred therefore in October, concurrently with the moose-hunting season. Wolves reduced the high seasonal variation in carcasses availability, and increased the carrion biomass during the critical time in spring when many scavenger species rear their young. In Finland, wolverines also presumably benefit from moose hunting in autumn, while the impact of wolf-killed moose on the diet of wolverines is greater during winter.

Our results indicate that in eastern Finland both wolverines and wolves avoid settlements. Preference for remote forest areas is consistent with results of previous studies on habitat selection and home-range use by wolverines (May et al. 2006, Krebs et al. 2007) and wolves (Theuerkauf et al. 2003, Kaartinen et al. 2010). Human activities have expanded leaving less living space for wolverines, which may be sensitive to human disturbance and also to habitat fragmentation (Carroll et al. 2001, Rowland et al. 2003). The disadvantageous effects of human activity on wolverines not only result from habitat loss, but also from the loss of prey species and other carnivore species that provide carrion (Landa et al. 2000).

Both wolverines and wolves appeared to avoid deciduous forests. According to the LAND-
SAT satellite data, the majority (66\%) of Finnish forests are mixed, with lower relative proportions of pure spruce $(15 \%)$, pure pine $(11 \%)$ and pure deciduous forests (8\%) (Lindfors \& Laurila 2000). Both studied species also selected other forest types in a similar way: they favoured coniferous and mixed forests and avoided young forests. Coniferous and mixed forests are very common in the study area. Avoidance of young forests by wolves was unexpected, because previous studies have demonstrated a tendency of wolves to select similar habitats to moose, their most important prey species (James et al. 2004).

Wolverine home-range areas and travel routes might enclose many different ecological conditions. One of the main future goals in wolverine management is to ensure the connectivity of sub-populations, and also maintain safe and favourable conditions along travel routes. Our results demonstrate the importance of remote forest areas and the presence of other carnivore species to wolverines, and provide information needed for the successful conservation management of wolverines in boreal-forest areas of Finland.

\section{Acknowledgements}

We would like to thank the thousands of volunteers who took part in the wildlife-triangle counts. Anni Koskela was personally funded by the Jenny and Antti Wihuri Foundation, Suomen Luonnonsuojelun Säätiö, Suomen RiistanhoitoSäätiö, and the Faculty of Science, University of Oulu.

\section{References}

Ahti, T., Hämet-Ahti, L. \& Jalas, J. 1968: Vegetation zones and their sections in northwestern Europe. - Annales Botanici Fennici 5: 169-211.

Baglione, V. \& Canestrari, D. 2009: Kleptoparasitism and temporal segregation of sympatric corvids foraging in a refuse dump. - Auk 126: 566-578.

Ballard, W. B., Carbyn, L. N. \& Smith, D. W. 2003: Wolf interactions with non-prey. - In: Mech, D. \& Boitani, L. (eds), Wolves: behaviour, ecology and conservation: 259-271. The University of Chicago Press, Chicago.

Banci, V. 1994: Wolverine. - In: Ruggiero, L. F., Aubry, K. B., Buskirk, S. W., Lyon, L. J. \& Zielinski, W. J. (eds.), The scientific basis for conserving forest carnivores: American marten, fisher, lynx and wolverine in the western United States: 99-127. Gen. Tech. Rept. RM-254, 
U.S. Dept. of Agric., For. Serv, Rocky Mountain Forest and Range Experiment Station. Ft. Collins, CO.

Brockmann, H. J. \& Barnard, C. J. 1979: Kleptoparatism in birds. - Animal Behaviour 27: 487-514.

Burnham, K. P. \& Anderson, D. R. 2002: Model selection and multimodel inference. A practical information-theoretic approach, 2nd ed. - Springer, New York.

Burnham, K. P. \& Anderson, D. R. 2004: Multimodel inference: understanding AIC and BIC in model selection. Sociological Methods \& Research 33: 261-304.

Carroll, C., Noss, R. \& Paquet, P. 2001: Carnivores as focal species for conservation planning in the Rocky Mountain Region. - Ecological Applications 11: 961-980.

Copeland, J. P. 1996: The biology of the wolverine in central Idaho. - M.Sc. thesis, University of Idaho, Moscow, Idaho.

Copeland, J. P., McKelvey, K. S., Aubry, K. B., Landa, A., Persson, J., Inman, R. M., Krebs, J., Lofroth, E., Golden, H., Squires, J. R., Magoun, A., Schwartz, M. K., Wilmot, J., Copeland, C. L., Yates, R. E., Kojola, I. \& May, R. 2010: The bioclimatic envelope of the wolverine (Gulo gulo): do climatic constraints limit its geographic distribution? - Canadian Journal of Zoology 88: 233-246.

Devault, T. L., Olson, Z. H., Beasley, J. C. \& Rhodes, O. E. 2011: Mesopredators dominate competition for carrion in an agricultural landscape. - Basic and Applied Ecology 12: 268-274.

Fielding, A. H. \& Haworth, P. F. 1995: Testing the generality of bird-habitat models. - Conservation Biology 9: 1466-1481.

Gorini, L., Linnell, J. D. C., May, R., Panzacchi, M., Boitani, L., Odden, M. \& Nilsen, E. B. 2012: Habitat heterogeneity and mammalian predator-prey interactions. Mammal Review 42: 55-77.

Greaves, R. K., Sanderson, R. A. \& Rushton, S. P. 2006: Predicting species occurrence using information-theoretic approaches and significance testing: an example of dormouse distribution in Cumbria, UK. - Biological Conservation 130: 239-250.

Green, R. H. 1979: Sampling design and statistical methods for environmental biologists. - John Wiley \& Sons, New York.

Heinrich, B. 1988: Winter foraging at carcasses by three sympatric corvids with emphasis on recruitment by the raven, Corvus corax. - Behavioral Ecology and Sociobiology 23: 141-156.

James, A. R. C., Boutin, S., Hebert, D. M. \& Rippin, A. B. 2004: Spatial separation of caribou from moose and its relation to predation by wolves. - Journal of Wildlife Management 68: 799-809.

Johnson, J. B. \& Omland, K. S. 2004: Model selection in ecology and evolution. - Trends in Ecology \& Evolution 19: 101-108.

Kaartinen, S., Luoto, M. \& Kojola, I. 2010: Selection of den sites by wolves in boreal forests in Finland. - Journal of Zoology 281: 99-104.

Klar, N., Fernández, N., Kramer-Schadt, S., Herrman, M., Trinzen, M., Büttner, I. \& Niemitz, C. 2008: Habitat selection models for European wildcat conservation. Biological Conservation 141: 308-319.
Kojola, I., Huitu, O., Toppinen, K., Heikura, K., Heikkinen, S. \& Ronkainen, S. 2004: Predation on European wild forest reindeer (Rangifer tarandus) by wolves (Canis lupus) in Finland. - Journal of Zoology 263: 229-235.

Krebs, J., Lofroth, E. \& Parfitt, I. 2007: Multiscale habitat use by wolverines in British Columbia, Canada. - Journal of Wildlife Management 71(7): 2180-2192.

Landa, A., Lindén, M. \& Kojola, I. 2000: Action plan for the conservation of wolverines (Gulo gulo) in Europe. - Nature and Environment 115, Council of Europe Publishing.

Landa, A. \& Skogland, T. 1995: The relationship between population density and body size of wolverines (Gulo gulo) in Scandinavia. - Wildlife Biology 1: 165-175.

Landa, A., Strand, O., Swenson, J. E. \& Skogland, T. 1997: Wolverines and their prey in southern Norway. - Canadian Journal of Zoology 75: 1292-1299.

Lindén, H., Helle, E., Helle, P. \& Wikman, M. 1996: Wildlife triangle scheme in Finland: methods and aims for monitoring wildlife populations. - Finnish Game Research 49: 4-11.

Lindfors, V. \& Laurila, T. 2000: Biogenic volatile organic compound (VOC) emissions from forests in Finland. Boreal Environment Research 5: 95-113.

Mattisson, J., Andrén, H., Persson, J. \& Segerström, P. 2011a: Influence of intraguild interactions on resource use by wolverines and Eurasian lynx. - Journal of Mammalogy 92: 1321-1330.

Mattisson, J., Persson, J., Andrén, H. \& Segerström, P. 2011b: Temporal and spatial interactions between an obligate predator, the Eurasian lynx (Lynx lynx), and a facultative scavenger, the wolverine (Gulo gulo). Canadian Journal of Zoology 89: 79-89.

May, R., Gorini, L., van Dijk, J., Brøseth, H., Linnell, J.C.D. \& Landa, A. 2012: Habitat characteristics associated with wolverine den sites in Norwegian multiple-use landscapes. - Journal of Zoology 287: 195-204.

May, R., Landa, A., van Dijk, J., Linnell, J. \& Andersen, R. 2006: Impact of infrastructure on habitat selection on wolverines Gulo gulo. — Wildlife Biology 12: 285-295.

May, R., van Dijk, J., Landa, A., Andersen, R. \& Andersen, R. 2010: Spatio-temporal ranging behaviour and its relevance to foraging strategies in wide-ranging wolverines. - Ecological Modelling 221: 936-943.

May, R., van Dijk, J., Wabakken, P., Swenson, J., Linnell, J., Zimmermann, B., Odden, J., Pedersen, H., Andersen, R. \& Landa, A. 2008: Habitat differentiation within the large-carnivore community of Norway's multiple-use landscapes. - Journal of Applied Ecology 45: 13821391.

Myhre, R. \& Myrberget, S. 1975: Diet of wolverine (Gulo gulo) in Norway. - Journal of Mammalogy 56: 752757.

Paquet, P. C. 1992: Prey use strategies of sympatric wolves and coyotes in Riding Mountain National Park, Manitoba. - Journal of Mammalogy 72: 337-343.

Pellikka, J., Rita, H. \& Lindén, H. 2005: Monitoring wildlife richness - Finnish applications based on wildlife triangle censuses. - Annales Zoologici Fennici 42: 123-134.

Persson, J., Ericsson, G. \& Segerström, P. 2009: Human 
caused mortality in the endangered Scandinavian wolverine population. - Biological Conservation 142: 325-331.

Pulliainen, E., Lindgren, E. \& Tunkkari, P. S. 1995: Influence of food availability and reproductive status on the diet and body condition of the European lynx in Finland. Acta Theriologica 40: 181-196.

Rassi, P., Hyvärinen, E., Juslén, A. \& Mannerkoski, I. (eds.) 2010: The 2010 Red List of Finnish Species. - Ministry of Environment \& Finnish Environment Institute, Helsinki.

Rowland, M., Wisdom, M., Johnson, D., Wales, B., Copeland, J. \& Edelman, F. 2003: Evaluation of landscape models for wolverines in the interior northwest, United States of America. - Journal of Mammalogy 84: 92-105.

Rushton, S. P., Ormerod, G. \& Kerby, G. 2004: New paradigms for modelling species distributions. - Journal of Applied Ecology 41: 193-200.

Sawyer, H., Nielson, R. M., Lindzey, F. \& McDonald, L. L. 2006: Winter habitat selection of mule deer before and during development of a natural gas field. - Journal of Wildlife Management 70: 396-403.

Selva, N., Jedrzejewska, B., Jedrzejewski, W. \& Wajrak, A. 2005: Factors affecting carcass use by a guild of scavengers in European temperate woodland. - Canadian Journal of Zoology 83: 1590-1601.

Stahler, D., Heinrich, B. \& Smith, D. 2002: Common ravens, Corvus corax, preferentially associate with grey wolves, Canis lupus, as a foraging strategy in winter. - Animal
Behaviour 64: 283-290.

Theuerkauf, J., Rouys, S. \& Jedrzejewski, W. 2003: Selection of den, rendezvous and resting sites by wolves in the Bialowieza Forest, Poland. - Canadian Journal of Zoology 81: 163-167.

Van Dijk, J., Andersen, T., May, R., Andersen, R. \& Landa, A. 2008a: Foraging strategies of wolverines within a predator guild. - Canadian Journal of Zoology 86: 966-975.

Van Dijk, J., Gustavsen, L., Mysterud, A., May, R., Flagstad, Ø., Broseth, H., Andersen, R., Andersen, R., Steen, H. \& Landa, A. 2008b: Diet shift of a facultative scavenger, the wolverine, following recolonization of wolves. Journal of Animal Ecology 77: 1183-1190.

White, K., Golden, H., Hundertmark, K. \& Lee, G. 2002: Predation by wolves, Canis lupus, on wolverines, Gulo gulo, and an American marten, Martes Americana, in Alaska. - Canadian Field-Naturalist 116: 132-134.

Wikenros, C. 2011: The return of the wolf. Effects on prey, competitors and scavengers. - Ph.D thesis, Swedish University of Agricultural Sciences.

Wilmers, C. C. \& Post, E. 2006: Predicting the influence of wolf-provided carrion on scavenger community dynamics under climate change scenarios. - Global Change Biology 12: 403-409.

Wilmers, C. C., Stahler, D. R., Crabtree, R. L., Smith, D. W. \& Getz, W. M. 2003: Resource dispersion and consumer dominance: scavenging at wolf- and hunter-killed carcasses in Greater Yellowstone, USA. - Ecology Letters 6: 996-1003. 